\title{
Article \\ Isothiazolinones as Novel Candidate Insecticides for the Control of Hemipteran Insects
}

\author{
Wenze He, Lilong Pan $(\mathbb{B}$, Wenhao Han and Xiaowei Wang *(1) \\ Ministry of Agriculture Key Laboratory of Molecular Biology of Crop Pathogens and Insects, Institute of Insect \\ Sciences, Zhejiang University, Hangzhou 310058, China; 12016107@zju.edu.cn (W.H.); panlilong@zju.edu.cn (L.P.); \\ wenhao_han@zju.edu.cn (W.H.) \\ * Correspondence: xwwang@zju.edu.cn
}

Citation: He, W.; Pan, L.; Han, W.; Wang, X. Isothiazolinones as Novel Candidate Insecticides for the Control of Hemipteran Insects. Antibiotics 2021, 10, 436. https://doi.org/ 10.3390/antibiotics10040436

Academic Editors: Roger C Levesque and Marc Maresca

Received: 20 March 2021

Accepted: 10 April 2021

Published: 14 April 2021

Publisher's Note: MDPI stays neutral with regard to jurisdictional claims in published maps and institutional affiliations.

Copyright: (c) 2021 by the authors. Licensee MDPI, Basel, Switzerland. This article is an open access article distributed under the terms and conditions of the Creative Commons Attribution (CC BY) license (https:/ / creativecommons.org/licenses/by/ $4.0 /)$.

\begin{abstract}
Hemipteran insects, such as whiteflies, aphids and planthoppers, resemble one of the most important pest groups threating food security. While many insecticides have been used to control these pests, many issues such as insecticide resistance have been found, highlighting the urgent need to develop novel insecticides. Here, we first observed that a commercial tetramycin solution was highly effective in killing whitefly. The major bioactive constituents were identified to be isothiazolinones, a group of biocides. We then tested the toxicity of several isothiazolinones to five hemipteran insects. The results show that Kathon, a widely used biocide against microorganisms, and its two constituents, chloromethylisothiazolinone (CMIT) and methylisothiazolinone (MIT), can cause considerable levels of mortality to whiteflies and aphids when applied at concentrations close to, or lower than, the upper limit of these chemicals permitted in cosmetic products. The results also indicate that two other isothiazolinones, benzisothiazolinone (BIT) and octylisothiazolinone (OIT) can cause considerable levels of mortality to whitefly and aphids but are less toxic than Kathon. Further, we show that Kathon marginally affects whitefly endosymbionts, suggesting its insecticidal activity is independent of its biocidal activity. These results suggest that some isothiazolinones are promising candidates for the development of a new class of insecticides for the control of hemipteran pests.
\end{abstract}

Keywords: benzisothiazolinone; hemiptera; insecticide; isothiazolinone; Kathon; octylisothiazolinone

\section{Introduction}

As the global population will continue to grow to roughly nine billion by the middle of this century, sustaining crop production is vital, which entails, among others, efficient crop protection against insect pests [1,2]. Among insect pests, hemipterans such as whiteflies, aphids and planthoppers, are one of the most significant groups threating food security as they damage crops directly by feeding and indirectly by transmitting plant diseases [3,4]. Some species of the Bemisia tabaci whitefly complex are pests of many crops worldwide [5,6]. Whitefly feeding on crops may result in reduced plant vigor and physiological perturbation; more importantly, whiteflies can transmit many plant viruses belonging to the genera Begomovirus (Geminiviridae), Crinivirus (Closteroviridae), Torradovirus (Secoviridae), among others [7-9]. Aphids represent a serious challenge for the sustainable production of many important cereal and vegetable crops; they can remove plant sap, secret phytotoxic salivary components and transmit viruses such as potyviruses [10]. Likewise, planthoppers are economically important pests of many cereals such as rice; they feed directly or serve as vectors of pathogenic microorganisms including viruses, resulting in significant crop damage and yield losses [11].

While the importance of integrated pest management is being increasingly realized, the application of chemical pesticides remains necessary, and in many cases, the only crop protection measure in agricultural practices [1]. Although many compounds, such as organophosphates, carbamates, pyrethroids, and more recently, neonicotinoids are effective 
in many circumstances, to control of hemipteran pests, extensive applications of these chemicals have led to the emergence of resistance in these insects in addition to off-target effects on non-target organisms and the environment [11-14]. Based on this scenario, it is imperative to develop new classes of insecticides, preferably with novel modes of action. However, nowadays the identification and development of new insecticides is accomplished by only a limited number of companies, probably due to the fact that the development of a new insecticide is often very costly, in terms of both financial input and time [15]. Hence, identifying new chemicals with insecticidal properties from existing compounds, presently not used as insecticides, may contribute to the development of novel insecticides.

Tetramycin was obtained from the fermentation of Streptomyces ahygroscopicus subsp. Wuzhouensis. It exhibits significant antibiotic activity against a wide range of microorganisms such as bacteria and fungi [16]. In China, tetramycin has been widely used to treat fungal diseases in plants [17]. In an experiment to eliminate endosymbionts in whiteflies, we accidentally noticed that treatment of whiteflies with a commercial tetramycin solution resulted in high mortality within $48 \mathrm{~h}$. Since tetramycin has no insecticidal activity, we postulated that some other components in the formulated tetramycin solution may kill whiteflies. We analyzed the tetramycin solution using Liquid chromatography-mass spectrometry (LC-MS) and surprisingly found that isothiazolinones were present in the solution and have insecticidal activity.

Isothiazolinones are a class of broad spectrum microbicides that have been widely used to control the growth of microorganisms such as bacteria, fungi and yeast in cooling water systems and cosmetics, among others [18]. However, whether they can be used as insecticides for the control of agricultural pests, remains unexplored. We tested the most widely used isothiazolinone Kathon, which is a combination of 5-chloro-2-methyl4-isothiazolin-3-one (Chloromethylisothiazolinone, CMIT) (Figure 1A) and 2-methyl-4isothiazolin-3-one (Methylisothiazolinone, MIT) (Figure 1B) in an approximate 3:1 ratio. We assessed the toxicity of Kathon to five species of hemipteran insects including three species from the B. tabaci whitefly complex, the green peach aphid Myzus persicae and the rice brown planthopper Nilaparvata lugens. Further, we assessed the toxicity of another two widely used isothiazolinones 1,2-Benzisothiazolin-3-One (Benzisothiazolinone, BIT) (Figure 1C) and 2-N-octyl-4-isothiazolin-3-one (Octylisothiazolinone, OIT) (Figure 1D) to whitefly and the green peach aphid. Finally, we explored the effects of Kathon treatment on the density of endosymbionts in whitefly. Our results provide novel insights into the insecticidal properties of isothiazolinones, and highlight the potential of these compounds in the development of novel insecticides for the control of hemipteran pests.

A<smiles>Cn1sc(Cl)cc1=O</smiles>

B

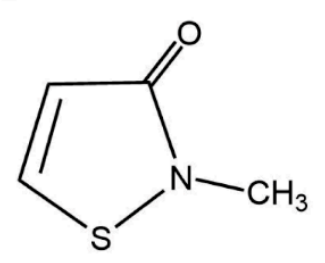<smiles>O=c1[nH]sc2ccccc12</smiles>

D<smiles>CCCCCCCCn1sccc1=O</smiles>

Figure 1. Chemical structure of CMIT (A), MIT (B), BIT (C) and OIT (D). 


\section{Materials and Methods}

2.1. Insects

Three species of whiteflies of the B. tabaci complex, namely Middle East-Asia Minor 1 (MEAM1), Mediterranean (MED) and Asia II 1, were tested. The mtCOI GenBank accession codes were KM821540 for MEAM1, GQ371165 for MED and DQ309077 for Asia II 1. A laboratory culture of each of the three species of whiteflies was originally established from field samples, collected in Zhejiang, China in 2012 (MEAM1), 2009 (MED) and 2010 (Asia II 1). Whiteflies were maintained on cotton plants (Gossypium hirsutum cv. Zhemian1793) in climate-controlled chambers at $26 \pm 2{ }^{\circ} \mathrm{C}, 60-80 \%$ relative humidity and a $14 / 10 \mathrm{~h}$ light/dark cycle without any contact with insecticides. Unless specified otherwise, adult whiteflies 1-7 days post emergence were used in the experiments.

A laboratory culture of the green peach aphid $M$. persicae was originally established from a field sample collected from field-grown tobacco plants (Nicotiana tabacum) on the Zijingang Campus of Zhejiang University, Hangzhou, China in 2018. The aphid culture was maintained on tobacco plants (N. tabacum cv. NC89) in a climate-controlled chamber at $23 \pm 2{ }^{\circ} \mathrm{C}, 50-60 \%$ relative humidity and a 16/8 h light/dark cycle without any contact with insecticides.

Test insects of the rice brown planthopper N. lugens were provided by Professor Hai-Jun Xu (Institute of Insect Sciences, Zhejiang University) [19]. The culture of brown planthopper was collected in 2008 and maintained thereafter on rice seedlings (Oryza sativa cv. Xiushui 134) in a climate-controlled chamber at $26 \pm 0.5^{\circ} \mathrm{C}, 50-60 \%$ relative humidity and a 16/8 h light/dark cycle without any contact with insecticides.

\subsection{Chemicals}

Tetramycin $(0.3 \%$ in water) was purchased from Liaoning Wkioc Bioengineering Co., Ltd. (Liaoning, China). Kathon (3\% in glycol) and MIT (Figure 1B) (9.5\% in water) were purchased from Sigma-Aldrich. CMIT (Figure 1A) (1.5\% in water), BIT (Figure 1C) (85\% in water) and OIT (Figure 1D) (100\%) were purchased from Hubei Jusheng Technology Co., Ltd. (Hubei, China). Acetamiprid (20\% in water) was purchased from Shandong Pharmaceutical Co., Ltd. (Shandong, China).

\subsection{Analysis of Insecticidal Activity of Tetramycin and Kathon against Whiteflies via Oral Route}

To assess the insecticidal activity of tetramycin solution against whitefly, $15 \%$ sucrose solutions containing 80, 40, 20, 10, 5 and $0 \mathrm{mg} / \mathrm{L}$ tetramycin were prepared. Similarly, $15 \%$ sucrose solutions containing 600.00, 300.00, 150.00 and $0 \mathrm{mg} / \mathrm{L}$ Kathon were prepared. Membrane feeding was conducted as mentioned before [20]. Five replicates were conducted for each concentration and 50 whiteflies were tested in each replicate.

\subsection{Liquid Chromatography-Mass Spectrometry (LC-MS)}

LC-MS was employed to identify the bioactive chemicals in tetramycin solution as reported before [21]. Waters Ultra Performance Liquid Chromatography (UPLC) and ACQUITY UPLC HSS SB-C18 column $(1.7 \mu \mathrm{m}, 2.1 \times 100 \mathrm{~mm})$ (Waters, MA, USA) was used in the chromatographic experiments. The mobile phases were $0.1 \%$ formic acid-water and $0.1 \%$ formic acid-acetonitrile. Sample injection volume, $3 \mu \mathrm{L}$; column oven temperature, $30{ }^{\circ} \mathrm{C}$; flow rate, $0.4 \mathrm{~mL} / \mathrm{min}$; and UV detector was set at $254 \mathrm{~nm}$. AB TripleTOF 5600plus System (AB SCIEX, Framingham, MA, USA) was employed for mass spectrometry. The optimal MS conditions: negative ion mode: Source voltage was $-4.5 \mathrm{kV}$, and the source temperature was $550^{\circ} \mathrm{C}$. Positive ion mode: Source voltage was $+5.5 \mathrm{kV}$, and the source temperature was $600^{\circ} \mathrm{C}$. Maximum allowed error was set to $\pm 5 \mathrm{ppm}$. Decluttering potential (DP), $100 \mathrm{~V}$; collision energy (CE), $10 \mathrm{~V}$. For MS/MS acquisition mode, the parameters were the same except that the collision energy (CE) was set at $40 \pm 20 \mathrm{~V}$, ion release delay (IRD) at 67, ion release width (IRW) at 25. The IDA-based auto-MS2 was performed on the eight most intense metabolite ions in a cycle of full scan (1s). The scan range of $m / z$ of precursor ion and product ion were set as 100-2000 Da and 50-2000 Da. The exact mass 
calibration was performed automatically before each analysis employing the Automated Calibration Delivery System. The data were analyzed using Peakview1.2 (AB SCIEX, Framingham, MA, USA).

\subsection{Analysis of Insecticidal Activity of Kathon against Whiteflies via Spraying}

To assess the insecticidal activity of Kathon against the adults of MEAM1 whitefly via spraying, the chemical was firstly diluted with water containing $1 \%$ surfactant (Tween-80) to six concentrations, namely $150.00,75.00,37.50,18.75$ and $9.38 \mathrm{mg} / \mathrm{L}$. Water containing $1 \%$ surfactant (Tween-80) was used as negative control, and Acetamiprid $(30.00 \mathrm{mg} / \mathrm{L}$ in water) was included as positive control. For MEAM1 nymphs, Asia II 1 and MED adults, 18.75 and $9.38 \mathrm{mg} / \mathrm{L}$ Kathon were used. For tests with whitefly adults, the test insects were confined on cotton leaves and then Kathon solutions were sprayed onto leaves. Specifically, in each replicate, approximately 100 whitefly adults were collected and released into a clip cage, which was covered with gauze and placed on the undersurface of a cotton leaf. Two hours later, live whiteflies were counted as the starting number of insects to be tested. The clip cage was then sprayed with a test solution using a hand-held sprayer as previously reported [22,23]. The gauze used allowed for efficient penetration of chemical solutions. For each of the four treatments of a whitefly species/stage, three replicates were conducted. Forty-eight hours later, the number of live and dead adult whiteflies were counted, and individuals were counted as dead when they were observed with a lack of discernible movement or obvious desiccation [24]. For the tests with MEAM1 whitefly nymphs, approximately 100 adult whiteflies were firstly collected and released into a clip cage placed on the undersurface of a cotton leaf. Fourteen days later, whitefly adults were removed, and the nymphs were then counted as the test insects (60-180 nymphs of all instars). Spray of Kathon solutions was then conducted as described above. The number of live nymphs was counted $48 \mathrm{~h}$ later, and dehydrated nymphs were considered dead.

\subsection{Insecticidal Activity of CMIT and MIT against MEAM1 Whitefly}

To assess the insecticidal activity of CMIT and MIT against MEAM1 whitefly adults, each of the two chemicals was diluted with water containing $1 \%$ surfactant (Tween-80) to two concentrations, namely 9.38 and $18.75 \mathrm{mg} / \mathrm{L}$. Negative and positive controls were prepared as described above. Protocols of application of the test solutions and observation of mortality were conducted via spraying as above for Kathon. For each of the four treatments of CMIT or MIT, five replicates were conducted.

\subsection{Insecticidal Activity of Kathon against the Green Peach Aphid}

Kathon solutions of various concentrations (18.75 and $9.38 \mathrm{mg} / \mathrm{L}$ ), negative (water containing $1 \%$ Tween- 80 ) and positive controls ( $30.00 \mathrm{mg} / \mathrm{L}$ Acetamiprid in water) were prepared, as described above. Leaves $\left(30-50 \mathrm{~cm}^{2}\right)$ of tobacco plants grown in greenhouses without any insecticide treatment were collected, soaked in Kathon solutions for $10 \mathrm{~s}$ and air-dried. Wingless aphid adults or nymphs were collected using a fine brush and placed onto the treated leaves, 15 individuals per leaf. The leaves were placed on agarose medium in $9 \mathrm{~cm}$ petri dishes to retain freshness. Live aphids were counted $48 \mathrm{~h}$ post transfer, and aphids that were completely immobile when touched upon or dehydrated were considered dead. For each of the four treatments for CMIT or MIT, three replicates were conducted.

\subsection{Insecticidal Activity of Kathon against the Rice Brown Planthopper}

A preliminary trial indicated that the rice brown planthopper was far less susceptible to Kathon than whiteflies or the green peach aphid. For the formal test, here, Kathon was diluted with water, containing the $1 \%$ surfactant (Tween- 80 ) to two concentrations, namely 150.00 and $300.00 \mathrm{mg} / \mathrm{L}$. Negative and positive controls were prepared, as described above. Rice plants that were grown in greenhouses without any insecticide treatment and at the booting stage were collected and washed thoroughly. Rice stems (about $10 \mathrm{~cm}$ in length) 
with roots were cut, air-dried, dipped in Kathon solutions in groups of three for $30 \mathrm{~s}$ and then air-dried again for $2 \mathrm{~h}$. The rice stems were then covered with moistened cotton wool around the roots and placed into $500 \mathrm{~mL}$ plastic cups, one group per cup. Next, 20 third-instar nymphs or adults of the rice brown planthopper were transferred into each plastic cup using a fine brush. Live planthoppers were counted at $48 \mathrm{~h}$ post transfer, and planthoppers that were completely immobile when touched upon or dehydrated were considered dead. Three replicates were conducted for each of the four treatments for adults or nymphs.

\subsection{Insecticidal Activity of BIT and OIT against the MEAM1 Whitefly and the Green Peach Aphid}

By consulting the results of a preliminary trial, BIT and OIT were diluted with water containing $1 \%$ surfactant (Tween-80) to a final concentration of $150.00 \mathrm{mg} / \mathrm{L}$. Negative and positive controls were prepared as described above. The mortality of MEAM1 whitefly adults or aphid adults was assessed as described above. Three replicates were conducted for each of the four treatments for the MEAM1 whitefly or the green peach aphid.

\subsection{Analysis of Relative Endosymbiont Density Following Kathon Treatment}

Kathon solutions of 4.69 and $9.38 \mathrm{mg} / \mathrm{L}$ were prepared and water containing $1 \%$ surfactant (Tween-80) was used as negative control. Whiteflies were collected and released into leaf-clip cages, and then Kathon solutions were applied by spraying as mentioned above. Forty-eight hours later, whiteflies were collected in groups of 15 and then subjected to DNA extraction and analysis of endosymbionts as reported before [25]. Briefly, lysis buffer (5 mmol/L of Tris- $\mathrm{HCl}$ ( $\mathrm{pH} 8.0), 0.5 \mathrm{mmol} / \mathrm{L}$ EDTA, $0.5 \%$ Nonidet P-40 and $1 \mathrm{mg} / \mathrm{mL}$ of proteinase K) was used for whitefly DNA extraction. Endosymbionts were quantified by quantitative real-time PCR (qPCR) with SYBR Premix Ex TaqTM (Takara, Japan) and Bio-Rad CFX96 Real- Time System (Bio-Rad, Hercules, CA, USA) with primers listed in Shan et al. (2019)

\subsection{Statistical Analysis}

For the analysis of whitefly mortality, all percentage data were arcsine square root transformed prior to statistical analysis, and back-transformed for presentation. Relative endosymbiont density was calculated as normalized to whitefly actin. For the comparisons of whitefly mortality and endosymbiont density among different treatments, one-way analysis of variance, followed by Fisher's least significance divergence (LSD) test was used. The differences between treatments were considered significant when $p<0.05$. All data are presented as mean \pm standard error of mean. All statistical analyses were performed using SPSS 20.0.

\section{Results}

\subsection{Effects of Tetramycin Treatment on the Survival of MEAM1 Whitefly via Oral Route and} Identification of Bioactive Constituents

We first explored the effects of tetramycin treatment on the survival of MEAM1 whitefly (Figure 2A). The mortality of whitefly increased with increasing concentrations of tetramycin, reaching $100.0 \%$ when the concentration was $80 \mathrm{mg} / \mathrm{L}$. Since no insecticidal activity of tetramycin has been reported, but has been used in the field for many years, we speculated some other components in the formulated tetramycin solution may be responsible for killing whiteflies. We used LC-MS and identified two chemicals in the formulated tetramycin solution we used (Figure 2B), and followed MS analysis identified these chemicals as 2- methyl-4-isothiazolin-3-one (Figure S1) and 2-methyl-4-isothiazolin-3one hydrochloride (Figure S2). Both chemicals are members of isothiazolinones, a group of broad-spectrum biocides. 
A

B
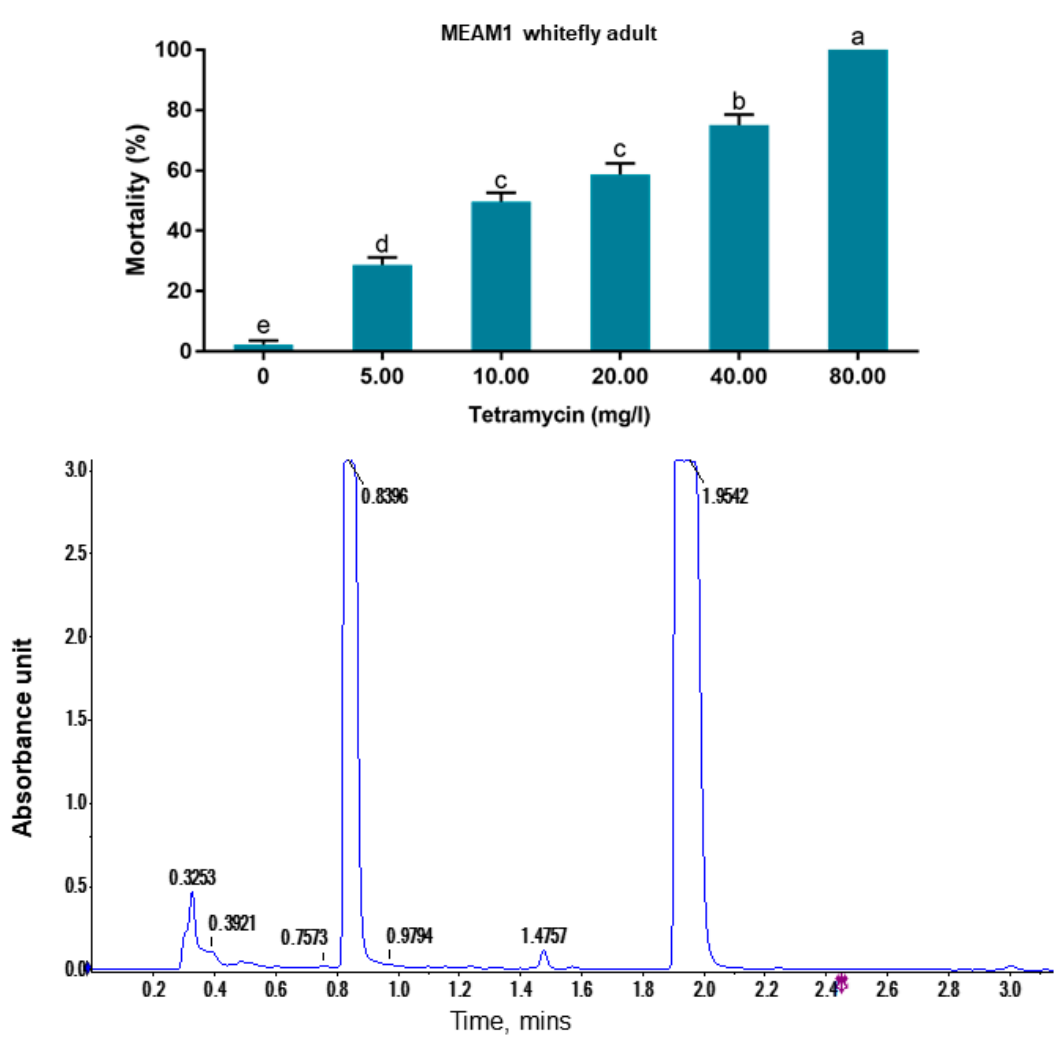

Figure 2. Effects of tetramycin treatment on whitefly survival and LC-MS analysis of the formulated tetramycin solution. Solutions of $15 \%$ sucrose, containing various concentration of formulated tetramycin solution were prepared and presented to whitefly orally by membrane feeding (A). LCMS analysis profile of formulated tetramycin solution (B). Different letters above bars in A indicate significant difference ( $p<0.05$, one-way analysis of variance and Fisher's LSD test). Peaks in B represent different chemicals detected in liquid chromatography.

\subsection{Effects of Kathon on the Survival of Three Species of Whiteflies}

We then tested the efficacy of Kathon, the most widely used isothiazoline with a combination of CMIT and MIT in an approximate 3:1 ratio, against the adults of MEAM1 whitefly via oral route, and found that Kathon killed $100 \%$ of whiteflies when concentrations were 600.00, 300.00 and $150.00 \mathrm{mg} / \mathrm{L}$ (Figure 3A). Next, a spraying method was employed for whitefly bioassay and lower concentrations were used. Acetamiprid were included as a positive control. When MEAM1 adults were treated with Kathon at the concentrations of 75.00, 37.50, 18.75 and $9.38 \mathrm{mg} / \mathrm{L}$, considerable levels of mortality were observed, though not as high as that observed with application of acetamiprid (Figure 3B). Likewise, treatment of MEAM1 whitefly nymphs with $18.75 \mathrm{mg} / \mathrm{L}$ Kathon, resulted in a considerable level of mortality, and no significant mortality was observed with the treatment of $9.38 \mathrm{mg} / \mathrm{L}$ Kathon (Figure 3C). Considerable levels of mortality were also observed in adults of both MED (Figure 3D) and Asia II 1 (Figure 3E) when they were treated with 9.38 and $18.75 \mathrm{mg} / \mathrm{L}$ Kathon. 
A

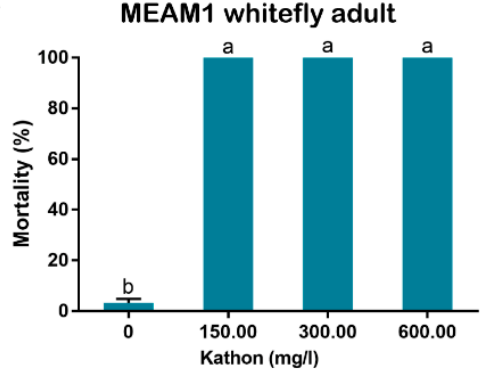

B

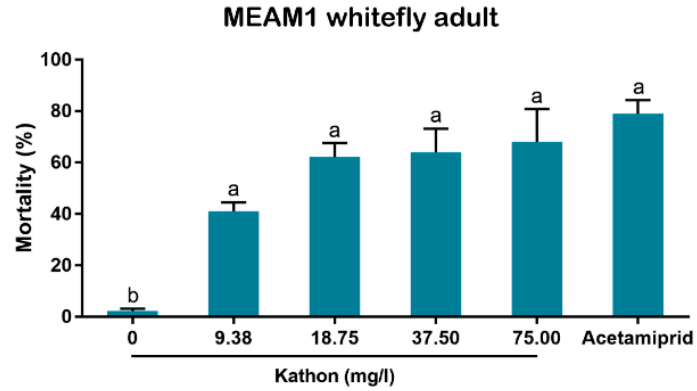

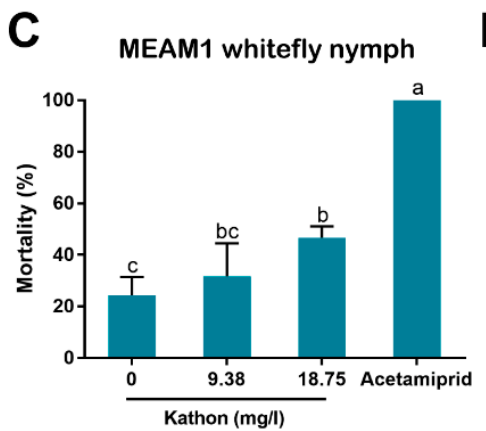

D

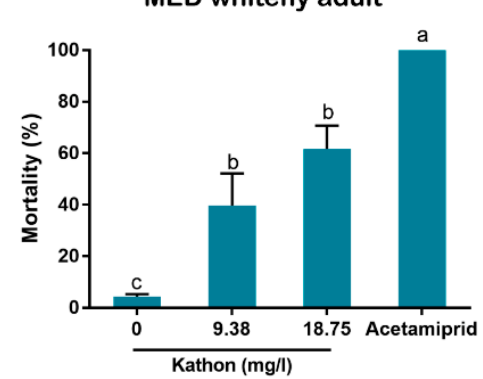

E

Asia II 1 whitefly adult

Figure 3. Effects of Kathon on the survival of three species of whiteflies of the Bemisia tabaci complex via oral route and spraying. Membrane feeding was conducted to determine the effects of Kathon on the survival of MEAM1 adults via oral route (A). Spraying application was performed for MEAM1 adults (B), MEAM1 nymphs (C), MED adults (D) and Asia II 1 adults (E). For spraying, Kathon was diluted with water containing 1\% surfactant (Tween-80) to two concentrations. Acetamiprid (30 mg/L) was used as positive control. The solutions were sprayed onto plants, and the mortality of whitefly adults and nymphs was assessed at $48 \mathrm{~h}$ post treatment. For each of the four treatments of a given whitefly species/stage, three replicates were conducted with each containing approximately 100 adults or 50-200 nymphs. Different letters above bars indicate significant difference ( $p<0.05$, one-way analysis of variance and Fisher's LSD test).

\subsection{Effects of CMIT and MIT on the Survival of MEAM1 Whitefly Adults}

To examine which components of Kathon have the insecticidal activity, we treated MEAM1 whitefly adults with CMIT or MIT individually at the concentrations of 9.38 and $18.75 \mathrm{mg} / \mathrm{L}$. Considerable levels of mortality were observed, though significantly lower than those observed following application of acetamiprid (Figure 4A,B).

A

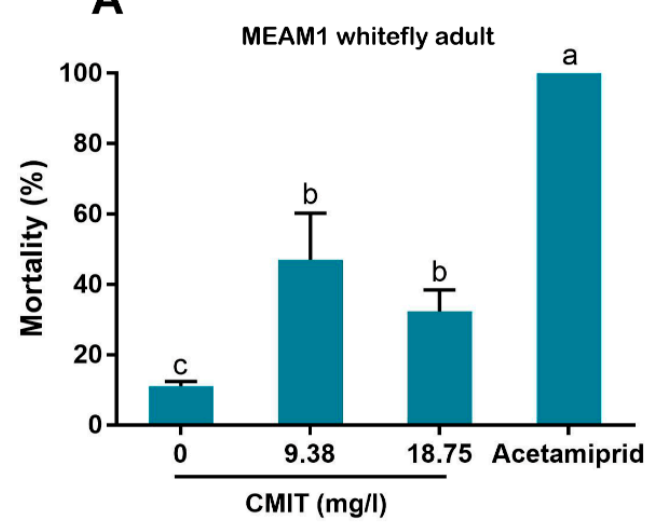

B

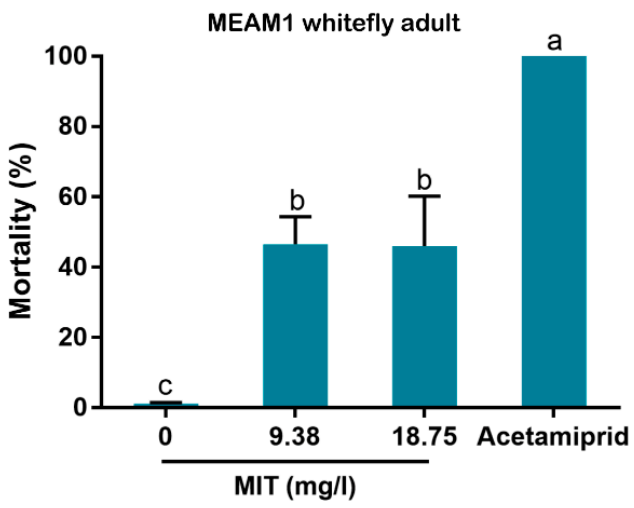

Figure 4. Effects of CMIT (A) and MIT (B) on the survival of MEAM1 adults. CMIT and MIT were diluted with water containing 1\% surfactant (Tween-80) to two concentrations, respectively. Acetamiprid: $30 \mathrm{mg} / \mathrm{L}$. The solutions were sprayed onto the plants, and the mortality of whitefly adults and nymphs was assessed at $48 \mathrm{~h}$ post treatment. For each of the four treatments for CMIT or MIT, five replicates were conducted on groups of approximately 100 adults or 50-200 nymphs. Different letters above bars indicate significant difference $(p<0.05$, one-way analysis of variance and Fisher's LSD test). 


\subsection{Effects of Kathon on the Survival of the Green Peach Aphid}

When aphid adults were treated with Kathon at concentrations of 9.38 and $18.75 \mathrm{mg} / \mathrm{L}$, the mortalities were $46.7 \%$ and $62.2 \%$ (Figure $5 \mathrm{~A}$ ). When aphid nymphs were treated with Kathon at 9.38 and $18.75 \mathrm{mg} / \mathrm{L}$, the mortalities were $46.7 \%$ and $66.7 \%$ (Figure $5 \mathrm{~B}$ ).

A

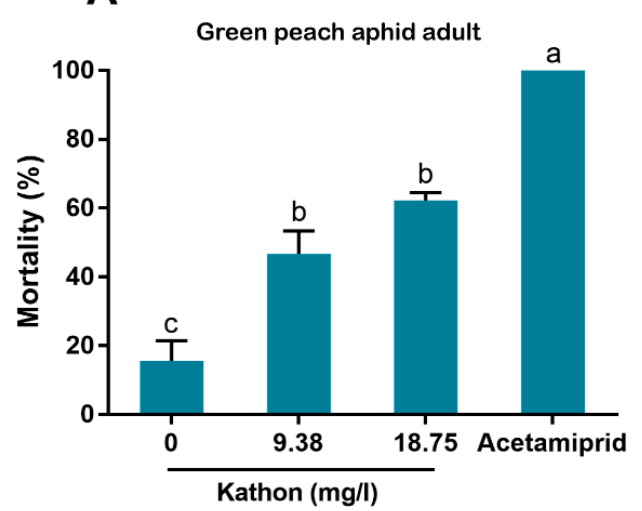

B

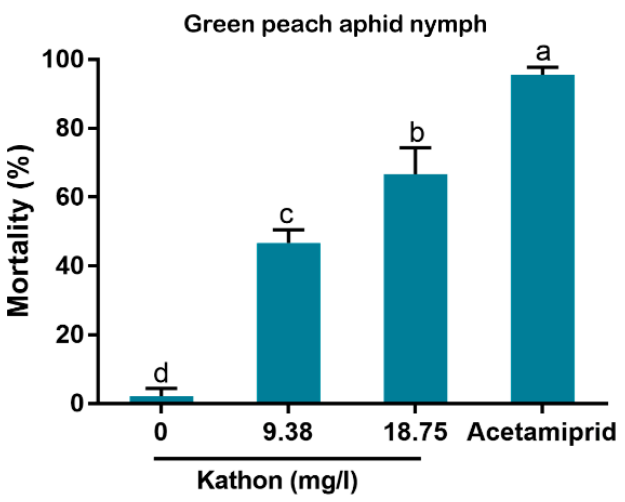

Figure 5. Effects of Kathon on the survival of the green peach aphid Myzus persicae: adult (A) and nymph (B). Acetamiprid $(30 \mathrm{mg} / \mathrm{L})$ was used as a positive control. The solutions were applied using dipping, and the mortality of aphid adults and nymphs was assessed at $48 \mathrm{~h}$ post treatment. For each of the four treatments of adult or nymph, three replicates were conducted on groups of 15 adults or nymphs. Different letters above bars indicate significant difference $(p<0.05$, one-way analysis of variance and Fisher's LSD test).

\subsection{Effects of Kathon on the Survival of the Rice Brown Planthopper}

As adults of the rice planthopper were treated with Kathon at a concentration of $300 \mathrm{mg} / \mathrm{L}$, a moderate level of mortality was observed, though significantly lower than that observed following application of acetamiprid. Whereas, no significant mortality was observed when treated with Kathon at the concentration of $150.00 \mathrm{mg} / \mathrm{L}$ (Figure 6A). Similarly, when nymphs of the rice brown planthopper were treated with Kathon at the concentrations of 150.00 and $300.00 \mathrm{mg} / \mathrm{L}$, moderate levels of mortality were observed and the level of mortality increased at the higher concentration, though still significantly lower than that observed following application of acetamiprid (Figure 6B).

A

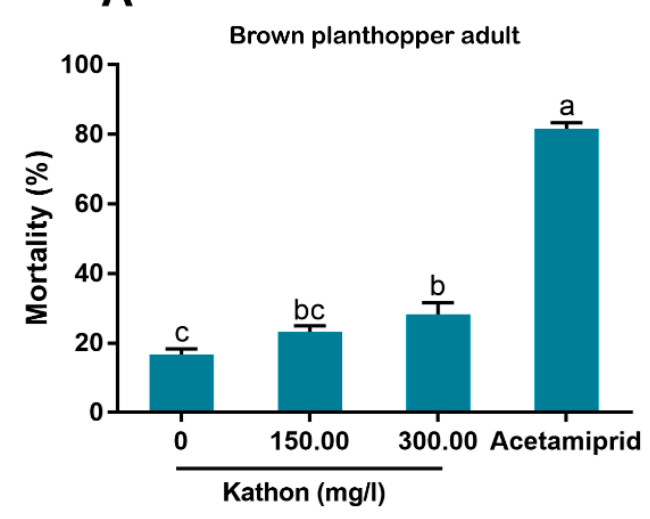

B

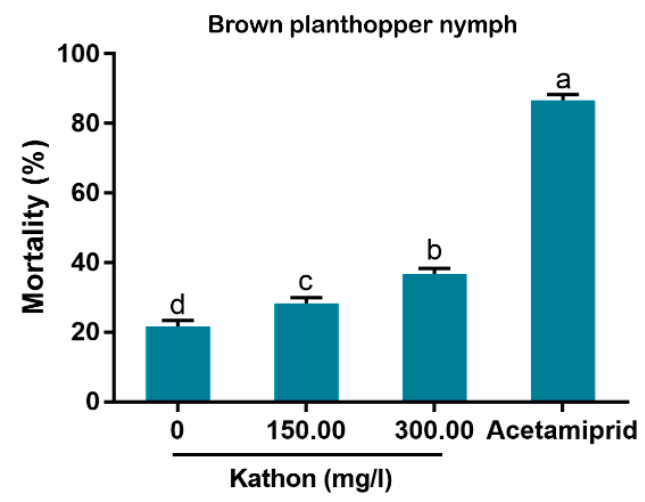

Figure 6. Effects of Kathon on the survival of rice brown planthopper Nilaparvata lugens: adult (A) and nymph (B). Acetamiprid (30 mg/L) was used as a positive control. The solutions were applied to rice-stems by dipping, and mortality of brown planthopper adults and nymphs was assessed at $48 \mathrm{~h}$ post treatment. For each of the four treatments of adults or nymphs, three replicates were conducted on groups of 20 individuals. Different letters above bars indicate significant difference $(p<0.05$, one-way analysis of variance and Fisher's LSD test). 


\subsection{Efficacy of BIT and OIT against Adults of the MEAM1 Whitefly and the Green Peach Aphid}

When adults of the MEAM1 whitefly were treated with BIT or OIT at a concentration of $150 \mathrm{mg} / \mathrm{L}$, considerable levels of mortality were observed, the mortality caused by OIT was significantly higher than that caused by BIT, but significantly lower than that observed following application of acetamiprid (Figure 7A). When adults of the green peach aphis were treated with BIT or OIT, high levels of mortality were observed, and the mortality caused by by BIT approached $100 \%$, which was observed following application of acetamiprid (Figure 7B).
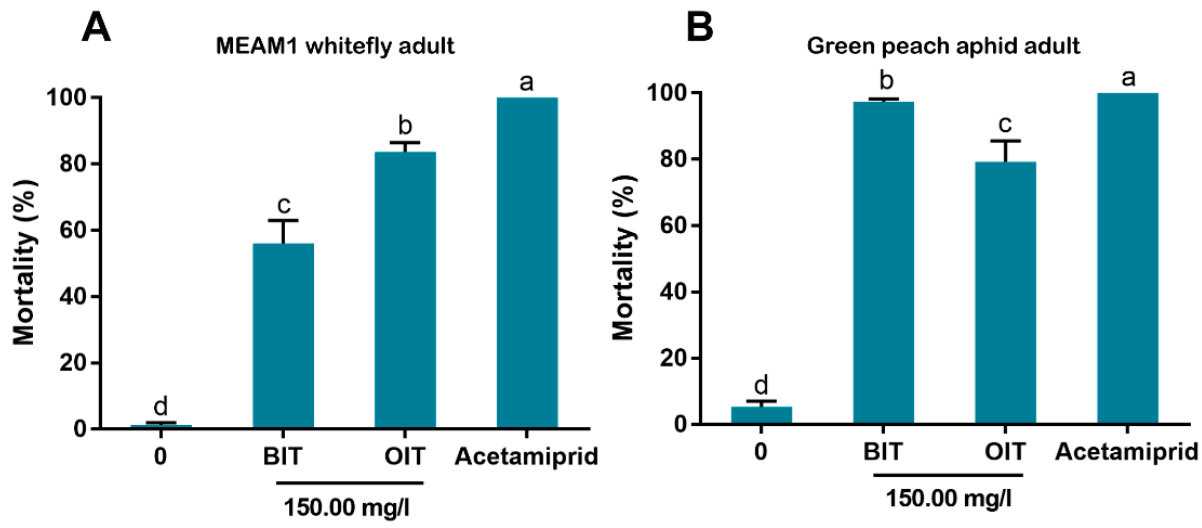

Figure 7. Effects of BIT and OIT on the survival of MEAM1 whitefly adults (A) and adults of the green peach aphid (B). Acetamiprid (30 mg/L) was used as a positive control. Whitefly and aphid mortality was recorded at $48 \mathrm{~h}$ post treatment. For each of the four treatments of the whitefly or aphid, three replicates were conducted. Each replicate of whitefly comprised approximately 100 adults and each replicate of aphid comprised 15 aphid adults. Different letters above bars indicate significant difference ( $p<0.05$, one-way analysis of variance and Fisher's LSD test).

\subsection{Effects of Kathon Treatment on the Density of Endosymbionts in Whitefly}

To explore whether Kathon treatment would affect the density of endosymbionts in whitefly, three endosymbionts Portiera, Hamiltonella and Rickettsia were analyzed. For the primary endosymbiont Portiera, Kathon treatment did not significantly change its density in whitefly (Figure 8A). Likewise, the density of secondary endosymbionts Hamiltonella did not significantly change upon Kathon treatment (Figure $8 \mathrm{~B}$ ). However, a significant decrease of Rickettsia density was observed; specifically, 9.38 and $4.69 \mathrm{mg} / \mathrm{L}$ Kathon treatment decreased Rickettsia density by $25.7 \%$, and $26.0 \%$, respectively (Figure 8 C).

A

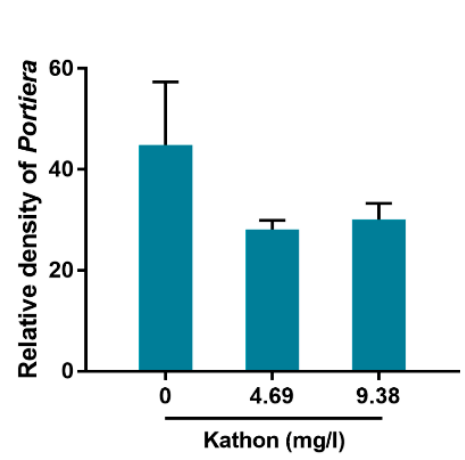

B

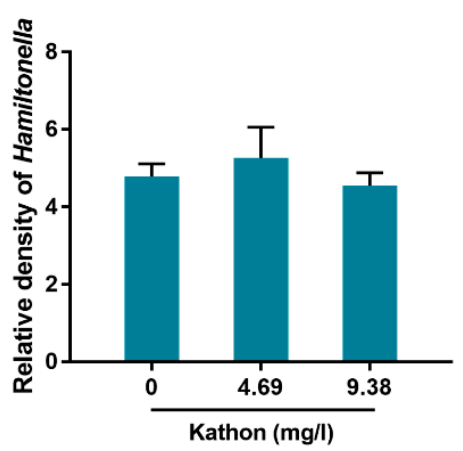

C

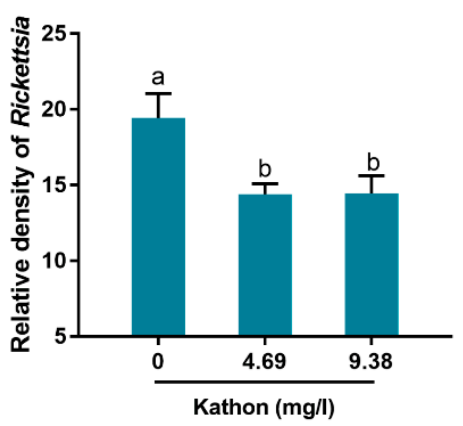

Figure 8. Effects of Kathon treatment on the density of endosymbionts in whitefly. Whiteflies were treatment with Kathon via spraying, and $48 \mathrm{~h}$ later the density of Portiera (A), Hamiltonella (B) and Rickettsia (C) were analyzed. Different letters above bars indicate significant difference $(p<0.05$, one-way analysis of variance and Fisher's LSD test). 


\section{Discussion}

In this study, we accidentally observed that a commercial formulated tetramycin solution can effectively kill whiteflies (Figure 2). In the process of tracing the insecticidal components in the tetramycin solution, we identified two isothiazoline biocides that exhibited insecticidal activity against whitefly. As isothiazoline is widely used as preservatives in many solutions [26], we presumed that it may have been added to the tetramycin solution during production. We next tested the effects of the most widely used isothiazoline biocide Kathon and its two constituents CMIT and MIT on the survival of five species of hemipteran insects.

In our bioassay, we first used high concentrations (up to $600 \mathrm{mg} / \mathrm{L}$ ) and then used lower concentrations by sequentially diluting the higher ones. Finally we chose 9.38 and $18.75 \mathrm{mg} / \mathrm{L}$ for bioassay as the European Union regulations on cosmetic products states that the upper limit of isothiazolinones such as Kathon in leave-on and rinse-off cosmetics is $15 \mathrm{mg} / \mathrm{L}$ [27]. Our results indicate that Kathon and its two constituents can cause considerable levels of mortality to three species of whiteflies from the B. tabaci complex and the green peach aphid when applied at the concentration close to, or lower than, the upper limit of these chemicals, permitted by the European Union regulations on cosmetic products (Figures 3-5). Interestingly, Kathon seemed to be more potent against whitefly, suggesting a synergistic effect between CMIT and MIT (Figures 3 and 4). Additionally, brown planthoppers seem to be less susceptible to Kathon than the other insects (Figure 6). The low susceptibility of brown planthoppers may be due to many reasons, for example the insect may degrade Kathon efficiently, among other. Nevertheless, further investigations are warranted to verify these hypotheses. The results also show that the two other isothiazolinones BIT and OIT were less toxic to the MEAM1 whitefly and the green peach aphid than Kathon and its two constituents (Figure 7). Overall, the data indicate that some isothiazolines can exert considerable levels of mortality on some hemipteran insects, such as whiteflies and aphids.

In recent decades, neonicotinoid insecticides have been widely used in the control of phloem-feeding insect pests, such as whiteflies, aphids and planthoppers $[13,14]$. The extensive application of neonicotinoids in the field has seen rapid development of insect resistance to insecticides of this class, such as imidacloprid and thiamethoxam [13,28]. Rotated application of insecticides with different modes of action has proven to be an effective strategy for managing resistance [28]. To implement this strategy, the development of new insecticides, with novel modes of action that are benign to the environment, is necessary. Isothiazolones inhibit microbial growth and metabolism by inhibiting critical physiological processes, such as respiration and energy generation [29-31]. Further, isothiazolones may react with many thiol-containing compounds such as cysteine, thereby forming disulfide derivatives and in turn promoting a series of reactions that impair key cellular functions $[29,31,32]$. While mechanisms underlying the toxicity of isothiazolones to hemipteran insects are unknown, disruption of critical cellular processes and interaction with thiol-containing compounds may both be possible. Nevertheless, the mechanisms of action are likely to differ significantly from those of neonicotinoids that act selectively on the insect central nerve system as agonists of the postsynaptic nicotinic acetylcholine receptors [14]. With regard to the mechanism of action, here we observed that isothiazolone treatment marginally affected the density of endosymbionts in whitefly. However, elimination of endosymbionts in hemipteran insects such as whitefly does not affect the survival of treated insects $[25,33,34]$. Hence, the microbicidal property of isothiazolones may contribute little, if any, to the insecticidal activity of these compounds.

Isothiazolinones are effective, fast-acting chemicals for the inhibition of microbial growth and metabolism and biofilm development. They are widely used for many industrial purposes and as a preservative in cosmetics including lipsticks and shampoo; under ambient conditions, isothiazolinones are quite stable as their estimated half-life is six months [26]. While isothiazolinones, such as Kathon have been reported to cause skin sensitization in humans and may induce apoptosis in human keratinocytes [35]. A review 
of case studies indicates that they are safe to human when the concentration is below $15 \mathrm{mg} / \mathrm{L}$ [18]. When plants were sprayed with isothiazolinones at the concentrations used in our experiments (up to $150 \mathrm{mg} / \mathrm{L}$ ), the plants did not suffer any appreciable sign of toxicity (data not shown). These results suggest that use of isothiazolinones as insecticides at a concentration lower than $15 \mathrm{mg} / \mathrm{L}$ may have limited risks to humans and crops. However, as broad spectrum biocides, isothiazolinones may significantly impact organisms other than insect pests. Therefore, investigations on the effects of isothiazolinones to non-target organisms are necessary in evaluating their potential use as insecticides.

Taken together, this study has identified the insecticidal properties of commonly used biocidal isothiazolinones including Kathon, BIT and OIT. Our findings indicate that isothiazolinones are promising candidates for the development of a new class of insecticides for the control of hemipteran pests.

Supplementary Materials: The following are available online at https:/ / www.mdpi.com/article/10 .3390 /antibiotics10040436/s1, Figure S1: MS ion chromatograms of the substance peaked at 0.8396 min in LC analysis and Figure S2: MS ion chromatograms of the substance peaked at $1.9542 \mathrm{~min}$ in LC analysis.

Author Contributions: X.W. and W.H. (Wenze He) conceived and designed research. W.H. (Wenze He), W.H. (Wenhao Han) and L.P. conducted experiments. W.H. (Wenze He) and L.P. analyzed data. W.H. (Wenze He) and L.P. wrote the manuscript. X.W. revised the manuscript. All authors have read and agreed to the published version of the manuscript.

Funding: Financial support for this study was provided by the National Natural Science Foundation of China (31925033) and the earmarked fund for China Agricultural Research System (grant number: CARS-23-D07).

Institutional Review Board Statement: Not applicable.

Informed Consent Statement: Not applicable.

Data Availability Statement: Data in this study is available upon request.

Acknowledgments: We thank Shu-Sheng Liu of our laboratory for advice and support throughout this study. We thank Zhi-Wei Ge from the Analysis Center of Agrobiology and Environmental Sciences of our university for assistance in LC-MS.

Conflicts of Interest: The authors declare no conflict of interest.

\section{References}

1. Chávez-Dulanto, P.N.; Thiry, A.A.; Glorio-Paulet, P.; Vögler, O.; Carvalho, F.P. Increasing the impact of science and technology to provide more people with healthier and safer food. Food Energy Secur. 2020, 10, e259. [CrossRef]

2. Godfray, H.C.J.; Beddington, J.R.; Crute, I.R.; Haddad, L.; Lawrence, D.; Muir, J.F.; Pretty, J.; Robinson, S.; Thomas, S.M.; Toulmin, C. Food security: The challenge of feeding 9 billion people. Science 2010, 327, 812-818. [CrossRef] [PubMed]

3. Hogenhout, S.A.; Ammar, E.D.; Whitfield, A.E.; Redinbaugh, M.G. Insect vector interactions with persistently transmitted viruses. Annu. Rev. Phytopathol. 2008, 46, 327-359. [CrossRef]

4. Lefeuvre, P.; Martin, D.P.; Elena, S.F.; Shepherd, D.N.; Roumagnac, P.; Varsani, A. Evolution and ecology of plant viruses. Nat. Rev. Microbiol. 2019, 17, 632-644. [CrossRef]

5. De Barro, P.J.; Liu, S.S.; Boykin, L.M.; Dinsdale, A.B. Bemisia tabaci: A statement of species stauts. Annu. Rev. Entomol. 2011, 56, 1-19. [CrossRef]

6. Kanakala, S.; Ghanim, M. Global genetic diversity and geographical distribution of Bemisia tabaci and its bacterial endosymbionts. PLoS ONE 2019, 14, e0213946. [CrossRef]

7. Oliveira, M.R.V.; Henneberry, T.J.; Anderson, P. History, current status, and collaborative research projects for Bemisia tabaci. Crop. Protect. 2001, 20, 709-723. [CrossRef]

8. Fiallo-Olivé, E.; Pan, L.L.; Liu, S.S.; Navas-Castillo, J. Transmission of begomoviruses and other whitefly-borne viruses: Dependence on the vector species. Phytopathology. 2020, 110, 10-17. [CrossRef]

9. Wang, X.W.; Blanc, S. Insect transmission of plant single-stranded DNA viruses. Annu. Rev. Entomol. 2021, 66, 389-405. [CrossRef] [PubMed]

10. Dedryver, C.; Ralec, A.L.; Fabre, F. The conflicting relationships between aphids and men: A review of aphid damage and control strategies. Comptes Rendus Biol. 2020, 333, 539-553. [CrossRef] [PubMed] 
11. Heong, K.L.; Hardy, B. Planthoppers: New Threats to the Sustainability of Intensive Rice Production Systems in Asia; International Rice Research Institute: Los Banos, Philippines, 2009; ISBN 978-971-22-0251-3.

12. Foster, S.P.; Denholm, I.; Devonshire, A.L. The ups and down of insecticides resistance in peach-potato aphids (Myzus persicae) in the UK. Crop. Protect. 2000, 19, 873-879. [CrossRef]

13. Goulson, D. An overview of the environmental risks posed by neonicotinoid insecticides. J. Appl Ecol. 2013, 50, 977-987. [CrossRef]

14. Jeschke, P.; Nauen, R.; Schindler, M.; Elbert, A. Overview of the status and global strategy for neonicotinoids. J. Agric. Food Chem. 2011, 59, 2897-2908. [CrossRef] [PubMed]

15. Sparks, T.C. Insecticide discovery: An evaluation and analysis. Pestic. Biochem. Physiol. 2013, 107, 8-17. [CrossRef] [PubMed]

16. He, Y.; Ding, Y.; Wu, Q.; Chen, M.; Zhao, S.; Zhang, J.; Wei, X.; Zhang, Y.; Bai, J.; Mo, S. Identification of the potential biological preservative tetramycin a-producing strain and enhancing its production. Front. Microbiol. 2020, 10, 2925. [CrossRef] [PubMed]

17. Gao, Y.Y.; He, L.F.; Li, X.X.; Lin, J.; Mu, W.; Liu, F. Toxicity and biochemical action of the antibiotic fungicide tetramycin on Colletotrichum scovillei. Pestic. Biochem. Physiol. 2018, 147, 51-58. [CrossRef] [PubMed]

18. Kim, M.K.; Kim, K.; Lee, J.Y.; Kwack, S.J.; Kwon, Y.C.; Kang, J.S.; Kim, H.S.; Lee, B. Risk assessment of 5-Chloro-2-Methylisothiazol3(2H)-One/2-Methylisothiazol-3(2H)-One (CMIT/MIT) used as a preservative in cosmetics. Toxicol. Res. 2019, 35, 103-117. [CrossRef]

19. Xue, J.; Zhou, X.; Zhang, C.X.; Yu, L.L.; Fan, H.W.; Wang, Z.; Xu, H.-J.; Xi, Y.; Zhu, Z.-R.; Zhou, W.-W.; et al. Genomes of the rice pest brown planthopper and its endosymbionts reveal complex complementary contributions for host adaptation. Genome Biol. 2014, 15, 521. [CrossRef]

20. Pan, L.L.; Chen, Q.F.; Zhao, J.J.; Guo, T.; Wang, X.W.; Hariton-Shalev, A.; Czosnek, H.; Liu, S.S. Clathrin-mediated endocytosis is involved in Tomato yellow leaf curl virus transport across the midgut barrier of its whitefly vector. Virology 2017, 502, 152-159. [CrossRef]

21. Chen, J.H.; Wu, H.J.; Xu, C.H.; Liu, X.C.; Huang, Z.; Chang, S.; Wang, W.; Han, G.; Kuang, T.; Shen, J.R.; et al. Architecture of the photosynthetic complex from a green sulfur bacterium. Science 2020, 370, eabb6350. [CrossRef]

22. Morita, M.; Ueda, T.; Yoneda, T.; Koyanagi, T.; Haga, T. Flonicamid, a novel insecticide with a rapid inhibitory effect on aphid feeding. Pest. Manag. Sci. 2007, 63, 969-973. [CrossRef]

23. Roditakis, E.; Stavrakaki, M.; Grispou, M.; Achimastou, A.; Waetermeulen, M.; Nauen, R.; Tsagkarakou, A. Flupyradifurone effectively manages whitefly Bemisia tabaci MED (Hemiptera: Aleyrodidae) and tomato yellow leaf curl virus in tomato. Pest. Manag. Sci. 2017, 7, 1574-1584. [CrossRef]

24. Sparks, T.C.; Riley, D.G.; Simmons, A.M.; Guo, L.Z. Comparison of toxicological bioassays for whiteflies. Insects 2020, 11, 789. [CrossRef] [PubMed]

25. Shan, H.W.; Luan, J.B.; Liu, Y.Q.; Douglas, A.E.; Liu, S.S. The inherited bacterial symbiont Hamiltonella influences the sex ratio of an insect host. Proc. R. Soc. B 2019, 286, 20191677. [CrossRef]

26. Silva, V.; Silva, C.; Soares, P.; Garrido, E.M.; Borges, F.; Garrido, J. Isothiazolinone biocides: Chemistry, biological, and toxicity profiles. Molecules 2020, 25, 991. [CrossRef]

27. Ozkaya, E.; Sayar, S.K.; Kobaner, G.B.; Pehlivan, G. Methylchloroisothiazolinone/methylisothiazolinone and methylisothiazolinone contact allergy: A 24-year, single-center, retrospective cohort study from Turkey. Contact Dermat. 2021, 84, 24-33. [CrossRef] [PubMed]

28. Horowitz, A.R.; Ghanim, M.; Roditakis, E.; Nauen, R.; Ishaaya, I. Insecticide resistance and its management in Bemisia tabaci species. J. Pest. Sci. 2020, 93, 893-910. [CrossRef]

29. Collier, P.J.; Ramsey, A.J.; Austin, P.; Gilbert, P. Growth inhibitory and biocidal activity of some isothiazolone biocides. J. Appl. Bacteriol. 1990, 69, 569-577. [CrossRef] [PubMed]

30. Fuller, S.J.; Denyer, S.P.; Hugo, W.B.; Pemberton, D.; Woodcock, P.M.; Buckley, A.J. The mode of action of 1,2-benzisothiazolin-3one on Staphylococcus aureus. Lett. Appl. Microbiol. 1985, 1, 13-15. [CrossRef]

31. Chapman, J.S.; Diehl, M.A. Methylchloroisothiazolone-induced growth inhibition and lethality in Escherichia coli. J. Appl. Microbiol. 1995, 78, 134-141. [CrossRef]

32. Williams, T. The mechanism of action of isothiazolinone biocides. PowerPlant Chem. 2007, 9, 14-22.

33. Shan, H.W.; Zhang, C.R.; Yan, T.T.; Tang, H.Q.; Wang, X.W.; Liu, S.S.; Liu, Y.Q. Temporal changes of symbiont density and host fitness after rifampicin treatment in a whitefly of the Bemisia tabaci species complex. Insect Sci. 2016, 23, 200-214. [CrossRef] [PubMed]

34. Zhang, C.R.; Shan, H.W.; Xiao, N.; Zhang, F.D.; Wang, X.W.; Liu, Y.Q.; Liu, S.S. Differential temporal changes of primary and secondary bacterial symbionts and whitefly host fitness following antibiotic treatments. Sci. Rep. 2015, 5, 15898. [CrossRef] [PubMed]

35. Ettorre, A.; Andreassi, M.; Anselmi, C.; Neri, P.; Andreassi, L.; Stefano, A.D. Involvement of oxidative stress in apoptosis induced by a mixture of isothiazolinones in normal human keratinocytes. J. Investig. Dermatol. 2003, 121, 328-336. [CrossRef] [PubMed] 